Article

\title{
The Economic Reality of Underutilised Crops for Climate Resilience, Food Security and Nutrition: Assessing Finger Millet Productivity in India
}

\author{
Christian Grovermann ${ }^{1, *}$, K. B. Umesh ${ }^{2}$, Sylvain Quiédeville ${ }^{1}$, B. Ganesh Kumar ${ }^{3}$ (1), \\ S. Sakamma ${ }^{2}$ and Simon Moakes ${ }^{1}$ \\ 1 Department of Socio-Economic Sciences, Research Institute of Organic Agriculture (FiBL), Ackerstrasse 113, \\ 5070 Frick, Switzerland; sylvain.quiedeville@fibl.org (S.Q.); simon.moakes@fibl.org (S.M.) \\ 2 Department of Agricultural Economics, University of Agricultural Sciences (UAS), Bangalore 560 065, India; \\ umeshuas@gmail.com (K.B.U.); saksri09@gmail.com (S.S.) \\ 3 National Academy of Agricultural Research Management (NAARM), Rajendranagar, Hyderabad 500030 , \\ India; ganesh@naarm.org.in \\ * Correspondence: christian.grovermann@fibl.org; Tel.: +41-62-865-0450
}

Received: 26 July 2018; Accepted: 23 August 2018; Published: 27 August 2018

check for updates

\begin{abstract}
In spite of the considerable potential contribution of neglected and underutilised crops to climate resilience, food security and nutrition; widespread adoption of these crops remains a challenge. Uptake is inhibited by poor economic performance due to low yields, compounded further by various social factors. Using farm survey data and aggregated time-series data from four states in southern India, this study examines factors influencing productivity in finger millet cultivation. A farm-level yield gap analysis is complemented by an analysis of total factor productivity (TFP) growth between 1999 and 2014 to better understand the role of research and innovation. Results suggest that there is considerable potential for improved growing practices to achieve better yields, but also education levels and technical support emerge as crucial factors for boosting finger millet productivity. The TFP analysis indicates a moderate level of growth, with a high variability and conflicting trends between states, suggesting a need to invest more in research and development, extension and infrastructure. Sustained productivity gains will require research efforts that respond to the needs expressed by farmers and that finger millet forms part of an overall strategy for sustainable intensification.
\end{abstract}

Keywords: finger millet; total factor productivity; tornqvist-theil index; yield gap analysis

\section{Introduction}

Agricultural research, development and policy continues to place a strong emphasis on increasing production of the three main staple crops (rice, wheat and maize); whilst public and private investment in other crops remains low [1]. There is a need for increased diversification of crop production to better address the issues of climate change, land degradation and sustainable diets. The combined potential of millets as both resilient crops for resource-constrained farmers and as a nutritious foodstuff for growing populations is huge across Asia and Africa [2-4]. Hence, millets are slowly being rediscovered by the agricultural research and development community. For instance, Bioversity International and the M.S. Swaminathan Research Foundation have worked since 2000 towards mainstreaming millets in India (https: / / www.bioversityinternational.org/news/detail/millet-revolution-in-india-lets-keepup-the-momentum/).The International Crop Research Institute for the Semi-Arid Tropics (ICRISAT) is now actively promoting them as "smart food" (http:/ / www.icrisat.org/wp-content/uploads/2017/ 04/Smart-food-flyer_Global_web.pdf). Policy-makers in India have also responded by incorporating millets into the National Food Security Act in 2013, making them available at a subsidised rate [5]. 
Minor millets are particularly neglected in terms of research and development. Their potential for climate smart agriculture and enhanced nutrition is also underexploited. Accounting for less than $1 \%$ of grains produced globally, they are nevertheless essential for food security in their respective agro-ecosystems, which are often marginal areas [6]. Minor millets are adapted to a range of growing conditions, mature quickly and are better able to withstand climatic extremes. High in micronutrients, including calcium, iron and dietary fibre, they also offer a greater variety of vitamins, contain more antioxidants and have more usable protein than wheat, rice or maize $[2,4,7,8]$.

Finger millet (Eleusine coracana L.) is the most widespread minor millet and an important staple food in many parts of India and Africa [9]. Across southern India, finger millet, locally known as ragi, traditionally played a central role in agriculture and diets. In recent decades it has, however, been on the decline. Despite the many positive characteristics, the area planted reduced by circa $20 \%$ and production declined by $18 \%$ between 1997 and 2013 [10]. However, it is still widely grown in Karnataka state (671,000 ha in 2013) and to a lesser extend in other states, such as Andhra Pradesh, Maharashtra and Tamil Nadu (286,000 ha altogether in 2013). These figures are in contrast with those for wheat and rice, for which production increases exceeded $20 \%$ in India during the same period.

Boosting crop diversification with minor millets requires an integrated strategy to overcome a range of obstacles. There is an apparent lack of awareness regarding its nutritional qualities among consumers. Furthermore, inadequate support by decision-makers has resulted in limited investment into research and development, as well as extension services $[2,11]$. Neglect of minor millets means that farmers growing them obtain lower returns as compared to other crops; however, there are substantial opportunities for increasing productivity and general economic performance. While annual yield increases in staples like rice and wheat are below $1 \%$ now and falling, the potential for yield increases in underutilised crops is substantial. Padulosi et al. [8] argue that directing greater research attention to nutritious cereals like millets would be a highly strategic and viable choice. It can offer great benefits in terms of lower input requirements, adaptation to climate change, and cultivation of marginal soils, along with social gains in terms of enhanced self-reliance of local populations and more resilient food systems. The authors affirm that, specifically with regard to minor millets, the yield gap is largely a reflection of existing cultivation techniques, for which ample room for improvement exists [8]. For example, optimised seeding can enhance yields and reduce menial fieldwork, especially among women, who play a key role in finger millet production. In this regard, well-functioning advisory services are of great importance.

Systematic studies of the determinants of productivity in minor millets are lacking. While finger millet yields have increased by $13 \%$ over the last decade in India, our farm survey data shows that the average yield gap between the best and lowest performing crops is considerable, lying at above $40 \%$ on average. It is thus essential to better understand the factors constraining productivity growth. Using a large farm household dataset, this paper examines the determinants of the yield gap in finger millet in southern India and identifies factors for tackling the disparity between the agronomic potential and the yields commonly achieved by the majority of farmers. To further examine the productivity of finger millet, we complement the farm-level yield gap assessment with an analysis of the trends in total factor productivity (TFP) growth at state level. Using publicly available data and following the approach proposed by the US Department of Agriculture [12], this analysis provides evidence of how far general productivity trends are driven by factors other than land expansion or input intensification. TFP reflects how efficiently inputs are transformed into outputs. Improvements in TFP are the result of technological change, improved technical and allocative efficiency in resource use, and scale economies [12]. A recent G20 white paper [13] highlights that productivity analysis based on accurate measurement of agricultural TFP is critical to identifying areas for improving policies that can influence long-term productivity growth in agriculture. These include investments in research and development, provision of advisory and financial services to promote the uptake of innovations, and the development of farmers' capacity to realise the potential of innovation. 
The paper continues in the next section by describing the study area and giving some details on the farm data that were collected, followed by an account of how yield gap and TFP were analysed. The subsequent section describes the results of the study. The paper concludes with a discussion of these results and conclusions.

\section{Material and Methods}

\subsection{Study Area and Farm-Level Data Collection}

As part of the Indo-Swiss Collaboration in Biotechnology (ISCB) project, the University of Agricultural Sciences, Bangalore, and the National Academy of Agricultural Research Management conducted a detailed farm household survey in 2016. Finger millet production information and selected household data were collected from 764 farms in southern India covering the four states where finger millet is most widely grown: Andhra Pradesh, Karnataka, Maharashtra, and Tamil Nadu. Together, these four states account for a finger millet cultivation area of circa 957,000 ha [2013 data], which is $83 \%$ of the cultivated area across India. This area provides the agricultural basis for approximately $1,830,000$ finger millet growers.

Regarding data collection, a cluster sampling approach was applied. In a first step, the districts with important finger millet production were purposively selected from among the 110 districts in the four aforementioned states. This was based on the criterion that the finger millet production area in the district exceeds 5000 ha. The selection resulted in a sub-set of 9 districts representing a finger millet cultivation area of circa 436,000 ha and a total number of approximately 800,000 finger millet growers. In a second step, a random sample of finger millet growers was approached in each of these districts, using set sampling numbers. Since these numbers in the district sub-samples are not directly indicative of the total number of finger millet growers per district or in the entire population, sampling weights were applied. The inverse probability of the selection of districts and finger millet growers was used to address the known shortcomings inherent in the sampling approach and more adequately reflect the importance of individual sampling units.

Prior to performing the yield gap analysis, data were cleaned and variables precisely specified to ensure full comparability between states. Data cleaning included the removal of severe outliers, identified as values higher than the upper quartile plus 3 times the interquartile range. These values were eliminated from the regression analysis. Nevertheless, the number of observations available for the regression analysis remained high at 723 . For a number of continuous independent variables (labour, machine labour use, mineral fertiliser, and manure fertiliser) a logarithmic transformation was used to normalise the distribution and to further reduce the effect of any outliers. To prevent zero value observations from being lost in the analysis, they were replaced by half the minimum non-zero quantity before taking logarithms. Due to the extreme non-normal distribution, the irrigation variable was transformed into a categorical variable. Consequently, two dummy variables were introduced in the regression (moderate and intensive irrigation), while no use was omitted. Farm household characteristics in the analysis included farm size, poverty status, as well as the age and education of the household head. Education was recorded in terms of level of qualifications achieved. Therefore, dummy variables were used to specify three education levels: no formal education, medium education corresponding to attendance of primary and middle school, and high education corresponding to secondary schooling and above. To examine the role of technical support for farmers by either state or private advisory services, a dummy variable indicating a perceived lack of such support was introduced in the analysis. Since the great majority of the farmers in the sample relied on local varieties, it was not possible to test the effect of improved varieties. It is important to note, however, that finger millet has received considerable attention among Indian breeders, with 62 improved varieties released by the Indian Council for Agricultural Research from 1986 to date.

For the calculation of the yield gap, reference yields are required for comparison. Rather than relying on data from cropping trials to assess the yield gap, the dependent variable was specified 
within the survey data. Yield gap was, therefore, calculated as the difference between actual yield and maximum yield, with the latter being defined by district as the average of yields found in the highest decile of the survey sample farm yields. Soil and climatic conditions vary considerably at state and district levels, but it was out of the scope of this study to estimate potential yields with detailed bio-physical data. Therefore, to account for varying agro-climatic conditions between the locations, we calculated a district-specific yield gap. Furthermore, we verified that the calculated maximum yields corresponded to the agronomic potential of finger millet.

The descriptive analysis of the data reveals that the average yield gap is considerable, ranging from $37 \%$ in Karnataka to $55 \%$ in Maharashtra (Table 1). In the latter, average yield was also lowest at 1.41 tons per hectare, while mean farm size is largest in Maharashtra at 4.62 hectares. In Karnataka farms are much smaller, at only 1.33 hectares on average.

Table 1. Summary statistics of variables used in the yield gap analysis.

\begin{tabular}{ccccccccc}
\hline & \multicolumn{2}{c}{$\begin{array}{c}\text { Andhra Pradesh } \\
(\boldsymbol{n}=\mathbf{1 8 1})\end{array}$} & \multicolumn{2}{c}{$\begin{array}{c}\text { Karnataka } \\
(\boldsymbol{n}=\mathbf{2 3 8})\end{array}$} & $\begin{array}{c}\text { Maharashtra } \\
(\boldsymbol{n}=\mathbf{1 0 6})\end{array}$ & $\begin{array}{c}\text { Tamil Nadu } \\
(\boldsymbol{n}=\mathbf{2 0 0})\end{array}$ \\
\cline { 2 - 9 } & Mean & $\mathbf{S D}^{\mathbf{1}}$ & Mean & SD & Mean & SD & Mean & SD \\
\hline Yield (tons per ha) & 1.82 & 1.18 & 2.45 & 0.78 & 1.41 & 0.65 & 2.22 & 0.74 \\
Yield gap (proportion) & 0.49 & 0.23 & 0.37 & 0.19 & 0.55 & 0.20 & 0.36 & 0.19 \\
Age (Years) & 48.39 & 9.63 & 53.43 & 14.25 & 49.31 & 10.89 & 48.37 & 13.30 \\
Education (0 = Low to 2 = High) & 0.83 & 0.79 & 1.17 & 0.71 & 0.87 & 0.78 & 0.69 & 0.78 \\
Below poverty line (yes = 1) & 0.99 & 0.07 & 0.42 & 0.49 & 1.00 & 0.00 & 0.69 & 0.47 \\
Lack of technical support (yes $=1)$ & 0.28 & 0.28 & 0.30 & 0.18 & 0.75 & 0.21 & 0.12 & 0.15 \\
Farm size (ha) & 3.19 & 2.17 & 1.33 & 0.66 & 4.62 & 4.06 & 3.05 & 2.28 \\
Irrigated area (\%) & 15.47 & 36.26 & 35.04 & 36.36 & 0.00 & 0.00 & 0.00 & 0.00 \\
Labour (person-days per ha) & 128.98 & 54.14 & 90.62 & 22.46 & 194.82 & 49.53 & 79.35 & 18.06 \\
Machine (person-hours per ha) & 3.77 & 3.50 & 11.53 & 6.49 & 6.05 & 3.65 & 16.30 & 8.97 \\
Mineral fertiliser (kg per ha) & 35.46 & 49.34 & 445.72 & 362.03 & 300.74 & 145.49 & 316.37 & 196.84 \\
Manure fertiliser (tons per ha) & 3.61 & 3.07 & 3.02 & 1.98 & 4.96 & 2.18 & 1.42 & 1.33 \\
Seed (kg per ha) & 15.33 & 7.78 & 19.87 & 11.13 & 2.28 & 1.07 & 32.40 & 11.88 \\
\hline
\end{tabular}

Mean input use (labour, fertiliser and seed) is highly variable across states, which can be explained by differences in agro-ecological conditions and the varying economic and dietary importance of finger millet.

\subsection{Econometric Yield Gap Estimation}

To identify the determinants of the yield gap in finger millet production a regression analysis was used. The outcome variable is expressed as a proportion (percent of yield gap). Therefore the maximum possible yield gap is one or $100 \%$, while zero indicates no yield gap. Due to the nature of the outcome variable and based on Papke and Wooldridge [14], a generalized linear model (GLM) with a binomial family for the error distribution and a logit link for the dependent variable was selected for the analysis. It was hypothesized that a greater input use is associated with a lower level of yield gap. Other determinants hypothesized to be associated with a reduced yield gap were: age, education and farm size. By contrast, living below the poverty line and a perceived lack of technical support through advisory services were expected to constrain farmers in closing their yield gap. The fit of the model was tested, and, based on the log pseudolikelihood of -317.47; the Akaike information criterion (AIC) for the regression was 0.925 , indicating a good fit.

\subsection{Assessment of Total Factor Productivity (TFP)}

TFP is considered the most informative measure of agricultural productivity. It takes into account the land, labour, capital, and material resources employed in farm production, while comparing them with the total value of crop and livestock output [12]. TFP measures the increase in total output that 
is not caused by an increase in quantity of inputs used. TFP growth approximates changes in the input quality, which refers to technological change, and also provides a good estimate of the technical efficiency [15]. TFP is different from a partial measure of productivity, which only takes account of a single input in comparison with the level of output.

Frontier and non-frontier approaches are the two most common ways of computing TFP and can be further distinguished in terms of their use of parametric or non-parametric techniques [16,17]. The frontier approach e.g., Hossain et al. [18] consists of estimating the frontier of input-output combinations. Under this approach, a positive change in TFP is generated by an outward shift of the frontier, in other words by better production possibilities either due to technological progress or technical efficiency improvements. Contrary to the frontier approach, the non-frontier approach assumes that companies are technically efficient. In this case, TFP growth is only determined by technological progress [19]. The rationale behind this assumption is that, in the long-term, businesses tend to find the most efficient combination of inputs-outputs through a continuous learning process.

Parametric techniques are based on estimating stochastic frontier models or on estimating production functions, using the time parameter as determinant of the evolving state of technology. The time parameter captures variations in productivity not due to changes in quantities of input use. In contrast, non-parametric techniques are based on linear programming or TFP indices. In particular the Tornqvist-Theil index is commonly used for growth accounting in the agricultural sector $[12,19,20]$.

Given the limited number of observations ( 15 for each state), the use of parametric methods was ruled out and the Tornqvist-Theil index was used to compute TFP growth. This provides evidence on technological change in finger millet production and allows inferences to the roles of research, innovation and dissemination efforts.

According to the Organization for Economic Cooperation and Development (OECD) [21], a Tornqvist-Theil index "is a weighted geometric average of the price relatives using arithmetic averages of the value shares in the two periods as weights". More specifically, the Tornqvist-Theil index is of interest to aggregate all inputs into a single variable [22]. This is made possible by summing up the monetary value of inputs, weighted by their share in the total cultivation cost, further adjusted by variations in the quantity used (more details thereafter). The Tornqvist-Theil index partly controls for changes in input prices and substitution effects [12], approximating changes in the state of technology through measuring the weighted differences in the growth rate of outputs and inputs that are expressed in natural logarithms [22]. The weights used are the share of revenue of the output and of the cost of inputs in relation to the total revenue and total production cost. Further details on the Törnqvist-Theil approach can be found, for example, in the work of Capalbo and Vo [22] and Coelli [23]. Using the Tornqvist-Theil index, TFP growth in our study was calculated as follows:

$$
\begin{gathered}
\text { TFP growth }(\%)=\ln \left(\frac{\mathrm{Qjt}}{\mathrm{Qjt}-1}\right)-\ln \left(\frac{\mathrm{QXit}}{\mathrm{Xit}-1}\right) \\
\ln \left(\frac{\mathrm{Q} j t}{\mathrm{Q} j t-1}\right)=1 / 2 \sum_{j=1}^{n}\left(\frac{\mathrm{P} j \mathrm{Q} j t}{\sum \mathrm{P} j \mathrm{Q} j t}+\frac{\mathrm{P} j t-1 \mathrm{Q} j t-1}{\mathrm{P} j \mathrm{t}-1 \mathrm{Q} j t-1}\right) \ln \left(\frac{\mathrm{Q} j t}{\mathrm{Q} j t-1}\right) \\
\ln \left(\frac{\mathrm{X} i t}{\mathrm{X} i t-1}\right)=1 / 2 \sum_{j=1}^{n}\left(\frac{\mathrm{C} i \mathrm{X} i t}{\sum \mathrm{C} i \mathrm{X} i t}+\frac{\mathrm{C} i t-1 \mathrm{X} i t-1}{\mathrm{C} i t-1 \mathrm{X} i t-1}\right) \ln \left(\frac{\mathrm{X} i t}{\mathrm{X} i t-1}\right)
\end{gathered}
$$

TFP growth represents the difference between the index of output growth and the index of input growth. The index of output growth equals half of the summed monetary value of each output [price (Pjt) multiplied by quantity $(\mathrm{Q} j t)]$ in the years $(t)$ and $(t-1)$, divided by the total revenue for finger millet (main grain and by-product), and multiplied by the variation in output (Qjt/Qjt - 1) between the year $(t)$ and $(t-1)$. The index of input growth equals half of the summed monetary value of each input [price (Xit) multiplied by quantity (Cit)] in the year $(t)$ and $(t-1)$, divided by the total production 
cost for finger millet, and multiplied by the variation in quantity used (Xit/Xit -1$)$ between the year $(t)$ and $(t-1)$.

Our analysis covers the period from 1999 to 2014 for the states of Andhra Pradesh, Karnataka, Maharashtra and Tamil Nadu, using available time-series output and input data specific to finger millet production, extracted from the website of the Indian Directorate of Economics and Statistics, Government of India [24]. Inflation rates for India were obtained from the website of the World Bank [25], and were used to deflate all monetary data (taking the year 1997 as basis).

The output and input growth indices were smoothed using the HP (Hodrick-Prescott) filter to help control for the important annual fluctuations in the level of output. The smoothed data series provide a better indicator of productivity trends in the long term [26].

\section{Results}

\subsection{Determinants of Yield Gap}

The regression results are presented in Table 2. Controlling for location, parameter signs were, with few exceptions, as hypothesized. In the regression output in Table 2 a negative value corresponds to a reduction in the yield gap, whilst a positive value indicates that a change in the variable increases the yield gap. While most effects were significant, age, medium education, living below the poverty line, and seed inputs did not have a significant impact on the yield gap. Location dummies for Karnataka, Maharashtra and Tamil Nadu all had positive signs (being significant for Karnataka and Maharashtra), indicating an increased yield gap in these states as compared to Andhra Pradesh, the omitted dummy variable, when controlling for all other effects.

Table 2. Determinants of yield gap in finger millet production (generalized linear model (GLM) estimation).

\begin{tabular}{|c|c|c|c|}
\hline Variables & Marginal Effects & SE $(\Delta \text {-method })^{5}$ & Sign $^{6}$ \\
\hline Age (years) & -0.05 & 0.00 & \\
\hline Education $(1=\text { medium })^{1}$ & -1.28 & 1.58 & \\
\hline Education $(1=\text { high })^{1}$ & -9.27 & 2.45 & $* * *$ \\
\hline Below poverty line $(1=$ yes $)$ & 0.78 & 1.00 & \\
\hline Lack of tech. support ( $1=$ yes $)$ & 8.66 & 3.36 & $* *$ \\
\hline Farm size (ha) & -0.87 & 0.15 & $* * *$ \\
\hline Irrigation $(1=\text { moderate })^{2}$ & -13.14 & 1.18 & $* * *$ \\
\hline Irrigation $(1=\text { intensive })^{2}$ & -21.97 & 2.46 & $* * *$ \\
\hline Labour (person-days/ha, ln) & -0.79 & 0.15 & $* * *$ \\
\hline Machine labour (person-days/ha, ln) & -0.08 & 0.38 & $* *$ \\
\hline Mineral fertiliser $(\mathrm{kg} / \mathrm{ha}, \mathrm{ln})$ & -0.33 & 0.05 & $* * *$ \\
\hline Manure fertiliser $(\mathrm{kg} / \mathrm{ha}, \ln )$ & -0.10 & 0.05 & $* *$ \\
\hline Seed $(\mathrm{kg} / \mathrm{ha}, \mathrm{ln})$ & 0.02 & 0.05 & \\
\hline Location 1 (1 = Karnataka $)^{3}$ & 13.51 & 4.26 & $* * *$ \\
\hline Location $2(1=\text { Maharashtra })^{3}$ & 26.98 & 4.42 & $* * *$ \\
\hline Location $3(1=\text { Tamil Nadu })^{3}$ & 1.06 & 6.78 & \\
\hline$N$ & 723 & & \\
\hline Log pseudolikelihood $^{4}$ & -317.47 & & \\
\hline
\end{tabular}

Notes: Dependent variable is yield gap in \%. ${ }^{1}$ Omitted education dummy is low education level. ${ }^{2}$ Omitted irrigation dummy is no irrigation. ${ }^{3}$ Omitted location dummy is Andhra Pradesh. ${ }^{4}$ The log pseudolikelihood is not reported when using survey weights, the coefficient refers to the model estimated without weights. ${ }^{5} \mathrm{SE}(\Delta-$ method) $=$ Standard error (calculated according to delta method). ${ }^{6}$ Significance levels: ${ }^{*} p<0.10,{ }^{* *} p<0.05,{ }^{* * *} p<0.01$.

The marginal effects in Table 2 are to be interpreted as the predicted change in yield gap for a one-unit change in covariate; for binary covariates this is a discrete change from zero to one. For example, high education is expected to result in a 9.27 percentage point reduction in yield gap compared to the baseline of low education. Lack of technical support on the contrary leads to a 
yield gap that is 8.66 percentage points higher. Larger farm size is associated with a lower yield gap, however the magnitude of the effect is relatively small. The input covariates irrigation, labour and fertiliser use led to the most substantial reductions in the yield gap. With all other variables held constant, the use of moderate irrigation (compared to no irrigation), could lower the yield gap by 13.14 percentage points, while intensive irrigation use could reduce the gap by 21.97 percentage points. Since labour, fertiliser and other input variables are expressed in logarithmic form, Table 2 reports marginal effects as percentage changes for these items. For instance, an additional 10\% labour input would lower the yield gap by 7.90 percentage points.

\subsection{TFP Growth}

The yield gap analysis demonstrates that input intensification, higher education and increased technical support are crucial factors at the farm-level. The analysis of TFP growth can improve the understanding of productivity issues at a more aggregate level and over time. Figure 1 shows trends for the four selected states in output, input and TFP growth for finger millet production between 1999 and 2014. A negative trend in TFP growth is apparent in Andhra Pradesh and Karnataka, while TFP growth is highly variable in the other two states. In Maharashtra and Tamil Nadu, there appears to be greater variation in output than in input growth. This difference may be due to the fact that the output growth can also be influenced by external factors, such as variations in the level of precipitation.
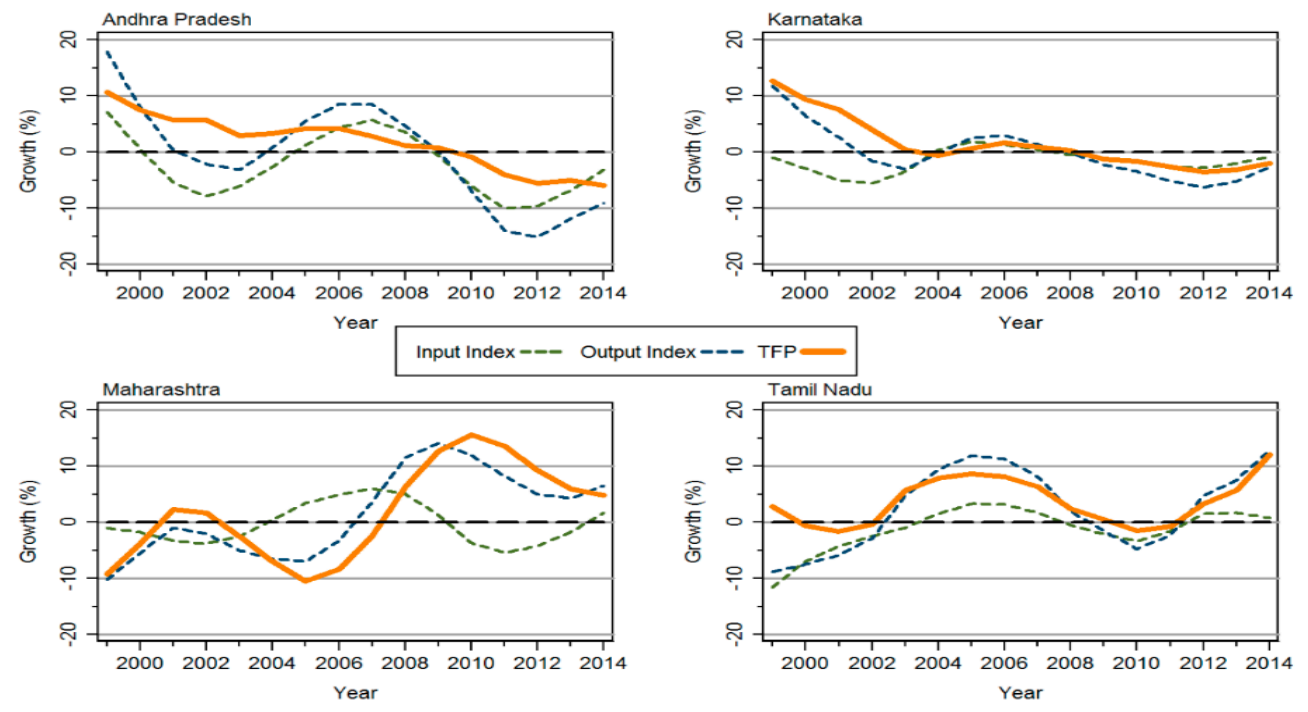

Figure 1. Smoothed input, output and total factor productivity (TFP) growth series for finger millet production between 1999 and 2014.

Table 3 indicates that despite annual variation and varying trends, on average TFP growth between 1999 and 2014 was positive for all of the states considered. The state of Tamil Nadu achieved the highest TFP growth during that period (3.61\%), whilst the other states had a positive change of around $1.5 \%$. It is interesting to emphasise that the trends in TFP growth were driven by a decrease in the annual input growth in the states of Karnataka and Andhra Pradesh, as in both instances annual output growth was also decreasing over time. By contrast, in the states of Tamil Nadu and Maharashtra, the TFP growth was mainly driven by an increase in output growth. 
Table 3. Input, output and total factor productivity (TFP) growth (\%) for finger millet production in four different periods.

\begin{tabular}{ccccc}
\hline State & Period & Output Growth (\%) & Input Growth (\%) & TFP Growth (\%) \\
\hline \multirow{5}{*}{ Andhra Pradesh } & $1999-2002$ & 5.75 & -1.58 & 7.42 \\
& $2003-2006$ & 2.84 & -0.83 & 3.69 \\
& $2007-2010$ & 1.49 & 0.56 & 0.98 \\
& $2011-2014$ & -12.54 & -7.43 & -5.13 \\
& $1999-2014$ & -0.88 & -2.37 & 1.64 \\
\hline \multirow{5}{*}{ Karnataka } & $1999-2002$ & 4.72 & -3.61 & 8.38 \\
& $2003-2006$ & 0.57 & 0.02 & 0.55 \\
& $2007-2010$ & -1.12 & -0.73 & -0.38 \\
& $2011-2014$ & -4.81 & -2.04 & -2.77 \\
& $1999-2014$ & -0.22 & -1.60 & 1.36 \\
\hline \multirow{5}{*}{ Maharashtra } & $1999-2002$ & -4.75 & -2.46 & -2.34 \\
& $2003-2006$ & -5.45 & 1.54 & -7.07 \\
& $2007-2010$ & 10.23 & 2.12 & 7.88 \\
& $2011-2014$ & 6.02 & -2.43 & 8.37 \\
& $1999-2014$ & 1.28 & -0.33 & 1.49 \\
\hline \multirow{6}{*}{ Tamil Nadu } & $1999-2002$ & -6.26 & -6.35 & 0.04 \\
& $2003-2006$ & 9.32 & 1.76 & 7.57 \\
& $2007-2010$ & 0.86 & -1.06 & 1.98 \\
& $2011-2014$ & 5.58 & 0.60 & 5.02 \\
\hline
\end{tabular}

Furthermore, the results show that there is considerable variability between different sub-periods (1999 to 2002; 2003 to 2006; 2007 to 2010; and 2011 to 2014). The results obtained for these sub-periods complement the trend lines in Figure 1, removing some of the variability observed from year to year.

TFP growth in the state of Tamil Nadu was always positive, despite a very low level in the period from 1999 to 2002. However, for the states of Karnataka and Andhra Pradesh there appears to be a negative trend, the average TFP growth for the entire period from 1999 to 2014 was slightly positive. The level of TFP growth of these states was very high from 1999 to $2002(>7 \%)$ before decreasing constantly. The TFP growth in the sub-period from 2007 to 2010 accounted for less than 1\% but was positive, whereas it declined quite considerably between 2010 and 2014 ( $-5 \%$ to $-3 \%$ ). The results obtained for the state of Karnataka show negative growth and are similar to those calculated by Kumar and Mittal [27], who assessed the period from 1986 to 2000. For the state of Tamil Nadu, however, different results emerged. In that state, our calculation indicates a TFP growth of almost 4\% from 1999 to 2014, while Kumar and Mittal [27] found TFP growth to be negative in the previous period from 1986 to 2000. As for the state of Maharashtra, there is no clear tendency even though we observe that TFP growth has been clearly positive since 2007 (around 8\%), reversing a negative earlier trend.

Since detailed data on research and extension systems for agriculture in India were not available at state level or were not specific to finger millet production, the likely determinants of the TFP growth are discussed in the following section.

\section{Discussion}

Enhancing the use of minor millets represents an important proposition to contribute to food security and dietary diversity [8]. It also represents an opportunity to increase productivity, especially in lower-performing areas. Reducing yields gaps in such parts of the world has been estimated to provide the basic caloric requirements for more than 800 million people [28]. However, the challenges to promoting widespread cultivation of finger millet are immense. The crop needs to be an economically viable solution for farmers in order to play a decisive role in contributing to climate resilience, food security and nutrition. 
Considerations on realising productivity gains in developing countries are often focused on increasing output through a more intensive use of farm inputs, mainly fertilisers (e.g., [29]). Our results show that it is necessary to address productivity challenges at various levels in order to make finger millet a more viable choice for farmers in southern India. Labour and fertiliser are crucial factors at the farm level. However, rather than suggesting a narrow focus on input intensification, the yield gap analysis indicates that investments in irrigation infrastructure, education and technical support services are of great importance. These investments should be enhanced as such aspects are also key to achieving consistent TFP growth [12]. The TFP analysis also suggests not only focusing on input intensification. While not explicit in the analysis, gender issues are an important consideration for a sustainable productivity growth strategy. Women play a crucial role in cultivation, processing, marketing and consumption of millets. Their involvement in variety development may ensure that needs are met in terms of maintaining or enhancing key crop characteristics.

The analysis of TFP data from 1999 to 2014 reveals a high variability and opposing trends across the region. While the development of TFP growth for finger millet is negative in Andrah Pradesh and Karnataka, it is positive in the other two states, reaching up to $3.61 \%$ on average for Tamil Nadu. Growth in Tamil Nadu and to a greater extend in Maharashtra has been unsteady, however. The negative trends in Andrah Pradesh and Karnataka and the variability in particular in Maharashtra point towards a need for technological and social innovations with regard to finger millet. Based on previous studies [12,30,31], the comparatively higher performance of Tamil Nadu in terms of TFP growth may be explained by factors such as research and development, advisory systems, education, governance and infrastructure. In this case, it may also be due to the fact that the initial productivity level was low in Tamil Nadu. In an analysis of productivity growth in major crops in Karnataka state for the period 1980 to 1995, Ananth [32] found that TFP growth was higher in crops that attracted higher research investments, such as rice, sugarcane and cotton. Further enquiry is necessary to establish the exact reasons for the observed trends. However, the lack of data, on agricultural research and extension expenditures and other possible TFP determinants, impedes a more precise assessment of what exactly caused the observed TFP growth patterns.

Regarding the TFP data itself, it should be noted that the results rely on the assumption that inputs and outputs were consistently and accurately recorded. In addition, using an index for the computation of TFP growth assumes competitive behaviour and constant returns to scale. In the context of finger millet production in southern India, this might not always be the case; our data does not provide any indications to the contrary, however.

Increasing research and development efforts is in line with information from the farm-level survey data. This revealed low levels of adoption of improved finger millet varieties in some states. Even with higher adoption of newer varieties, such as the GPU28 variety in Karnataka, TFP growth is not assured. Therefore, the development of new cultivars alone is insufficient, but research needs to be integrated into an approach that facilitates the adoption of appropriate growing practices and develops market opportunities. Results by Fischer et al. [2] confirm this. At the moment, there is an apparent disconnect between research outputs and uptake, which urgently needs to be addressed. Varieties released by research organisations should clearly respond to the demands of farmers in terms of growing requirements, but also in terms of quality and taste, as finger millet is often grown for home consumption. Advisory services need to be strengthened in order to support farmers to articulate their needs and use appropriate cultivation techniques, such as line sowing and timely and precise fertilising. This can help to reduce labour requirements, achieve better yields and maintain finger millet as part of relatively diverse rotation, avoiding the trend of specialisation and monocultures. Finger millet provides farmers with a climate-resilient crop that fits well into a mixed farming system involving livestock. Its hardiness and nutritional properties make it a strategic crop for ensuring food security. Nevertheless, for finger millet production to be maintained or enhanced, increased yields must be achieved by the adoption of new varieties and good practice in agronomic techniques. Further 
research is required into approaches that deliver productivity growth and guarantee the nutrition benefits of finger millet.

Finger millet is still consumed as a main foodstuff in large parts of southern India, and efforts are under way to increase the appeal of finger millet for consumers, also in urban areas. Besides awareness campaigns on the dietary benefits, biofortification is seen as a way to boost consumption and achieve better nutrition outcomes. Ongoing research under the ISCB, using consumer auctions, shows that there is an increased willingness to pay for an improved finger millet with higher iron availability. A study by Pallante et al. [11] illustrated the potential for developing niche markets for finger millet. These opportunities, however, depend on how effectively and widespread consumer information regarding the beneficial nutritional aspects can be communicated and reach specific target groups of consumers, for instance those affected by anaemia or young people. The social stigma attached to millets, considered often as 'food of the poor' especially by the younger generation, requires specially targeted awareness campaigns; for instance, involving known chefs who fuse traditional crops with modern cuisine.

\section{Conclusions}

Additional studies are required on the acceptance of farmers of specific finger millet varieties and the factors that influence adoption. Achieving sustained productivity gains is only possible if research better responds to the needs expressed by farmers and if the crop is meaningfully embedded in an overall strategy for sustainable intensification of production and sustainable diets. Only if the various economic and social constraints can be sufficiently addressed will it be possible to harness the potential of underutilised crops, such as finger millet, for climate resilience, food security and nutrition. This study illustrates the need to sustain and intensify investments in infrastructure, including irrigation, as well as in education, technical support services, and more generally in needs-based agricultural research and development.

Supplementary Materials: The dataset used for the yield gap analysis in this study is available from the corresponding author on reasonable request. The dataset used for the TFP analysis is available from the website of the Government of India's Directorate of Economics and Statistics (http://eands.dacnet.nic.in/). Agricultural production statistics are available from http://aps.dac.gov.in/APY/Public_Report1.aspx.

Author Contributions: The paper was conceived and developed by C.G., K.B.U. and S.Q. with inputs by S.M., S.S. and B.G.K., C.G. analysed the yield gap data, while S.Q. analysed the TFP data. K.B.U., B.G.K. and S.S. carried out the data collection and supported the analysis. S.M. proofread and edited the draft paper. All authors read and approved the final manuscript.

Funding: This research was funded through the Indo-Swiss Cooperation on Biotechnology (ISCB) programme.

Acknowledgments: The authors would like to acknowledge Matthias Stolze (FiBL Switzerland) and Sheshshayee Sreeman (UAS Bangalore) for their guidance on the research conducted under the ISCB programme. In addition, the authors want to thank the agriculture economics students of UAS Bangalore for their support with the data collection and data entry.

Conflicts of Interest: The authors declare no conflict of interest.

\section{References}

1. Pingali, P. Agricultural policy and nutrition outcomes-getting beyond the preoccupation with staple grains. Food Secur. 2015, 7, 583-591. [CrossRef]

2. Fischer, H.W.; Reddy, N.N.L.; Rao, M.L.S. Can more drought resistant crops promote more climate secure agriculture? Prospects and challenges of millet cultivation in Ananthapur, Andhra Pradesh. World Dev. Perspect. 2016, 2, 5-10. [CrossRef]

3. International Crops Research Institute for the Semi-Arid Tropics (ICRISAT)/Food and Agriculture Organization (FAO). The World Sorghum and Millet Economies; ICRISAT: Patancheru, India, 2016.

4. Taylor, J.; Schober, T.; Bean, S. Novel food and non-food uses for sorghum and millets. J. Cereal Sci. 2006, 44, 252-271. [CrossRef] 
5. The National Food Security Bill, Gazette of India, Extraordinary, Part-II, Section-1, 10 September 2013, Act No. 20 of 20 Indian Council of Agricultural Research 2017, DARE/ICAR Annual Reports. Available online: http:/ / indiacode.nic.in/acts-in-pdf/202013.pdf (accessed on 8 November 2017).

6. Mal, B.; Padulosi, S.; Bala Ravi, S. Minor Millets in South Asia: Learnings from IFAD-NUS Project in India and Nepal; Bioversity International, Maccarese, Rome, Italy and the M.S. Swaminathan Research Foundation: Chennai, India, 2010.

7. Ravi, S.B.; Hrideek, T.K.; Kumar, A.T.K.; Prabhakaran, T.R.; Mal, B.; Padulosi, S. Mobilizing neglected and underutilized crops to strengthen food security and alleviate poverty in India. Indian J. Plant Genet. Resour. 2010, 23, 110-116.

8. Padulosi, S.; Mal, B.; King, O.I.; Gotor, E. Minor millets as a central element for sustainably enhanced incomes, empowerment, and nutrition in rural India. Sustainability 2015, 7, 8904-8933. [CrossRef]

9. Sorghum, F.A.O. Millets in Human Nutrition; UN Food and Agriculture Organisation: Rome, Italy, 1995; ISBN 92-5-103381-1.

10. Web Based Land Use Statistics Information System, Directorate of Economics and Statistics, Government of India. Available online: http:/ /aps.dac.gov.in/LUS/Public/Reports.aspx (accessed on 8 November 2017).

11. Pallante, G.; Drucker, A.G.; Sthaphit, S. Assessing the potential for niche market development to contribute to farmers' livelihoods and agrobiodiversity conservation: Insights from the finger millet case study in Nepal. Ecol. Econ. 2016, 130, 92-105. [CrossRef]

12. Fuglie, K. Accounting for growth in global agriculture. Bio-Based App. Econ. 2015, 4, 201-234. [CrossRef]

13. Fuglie, K.; Benton, T.; Sheng, Y.; Hardelin, J.; Mondelaers, K.; Laborde, D. Metrics of Sustainable Agricultural Productivity, G20 MACS White Paper. Available online: https://www.oecd.org/tad/events/G20\% 20MACS\%20WP\%20Ag\%20Productivity\%20Metrics\%204-26-2016_Final.pdf (accessed on 8 November 2017).

14. Papke, L.E.; Wooldridge, J.M. Econometric Methods for Fractional Response Variables with an Application to 401(k) Plan Participation Rates. J. Appl. Econ. 1996, 11, 619-623. [CrossRef]

15. Dhehibi, B. The Effect of trade liberalization on the sustainability of agricultural sectors in Egypt and Tunisia: A new framework based on TFP growth structure. In Building Sustainable Agriculture for Food Security in the Euro-Mediterranean Area: Challenges and Policy Options; Edizioni Nuova Cultura: Roma, Italy, 2015; pp. 179-201.

16. Mahadevan, R. To Measure or Not to Measure Total Factor Productivity Growth? Oxf. Dev. Stud. 2003, 31, 365-378. [CrossRef]

17. Kellermann, M.A. Total Factor Productivity Decomposition and Unobserved Heterogeneity in Stochastic Frontier Models. Agric. Resour. Econ. Rev. 2015, 44, 124-148. [CrossRef]

18. Hossain, M.K.; Kamil, A.A.; Baten, M.A.; Mustafa, A. Stochastic frontier approach and data envelopment analysis to total factor productivity and efficiency measurement of Bangladeshi rice. PLoS ONE 2015, 7, e46081. [CrossRef] [PubMed]

19. Mahadevan, R. The Economics of Productivity in Asia and Australia; Edward Elgar: Cheltenham, UK, 2004.

20. Fuglie, K.; Wang, S.L.; Ball, V.E. Productivity Growth in Agriculture: An International Perspective; CABI: Wallingford, UK, 2012.

21. OECD Glossary of Statistical Terms-Törnqvist Price Index. Available online: https:/ / stats.oecd.org/glossary / detail.asp?ID=2711 (accessed on 10 August 2017).

22. Capalbo, S.; Vo, T. A review of evidence on agricultural productivity and aggregate technology. In Agricultural Productivity Measurement and Explanation; Capalbo, S., Antle, J., Eds.; Resources for the Future: Washington, DC, USA, 1998; pp. 96-137.

23. Coelli, T.J. Measurement of total factor productivity growth and biases in technological change in western Australian agriculture. J. Appl. Econ. 1996, 11, 77-91. [CrossRef]

24. District-Wise, Season-Wise Crop Production Statistics from 1997. Ministry of Agriculture and Farmers Welfare. Available online: https:/ / data.gov.in/catalog/district-wise-season-wise-crop-production-statistics (accessed on 8 November 2017).

25. Inflation, Consumer Prices (Annual \%). Available online: http://data.worldbank.org/indicator/FP.CPI. TOTL.ZG (accessed on 10 August 2017).

26. Methodology for Measuring International Agricultural Total Factor Productivity (TFP). Available online: https: / / www.ers.usda.gov/data-products/international-agricultural-productivity / documentationand-methods / (accessed on 8 November 2017). 
27. Agricultural Productivity Trends in India: Sustainability Issues, Agricultural Economics Research Review. Available online: https://ageconsearch.umn.edu/bitstream/57779/2/DrP-Kumar.pdf (accessed on 8 November 2017).

28. West, P.C.; Gerber, J.S.; Engstrom, P.M.; Mueller, N.D.; Brauman, K.A.; Carlson, K.M.; Cassidy, E.S.; Johnston, M.; MacDonald, G.K.; Ray, D.K.; et al. Leverage points for improving global food security and the environment. Science 2014, 345, 325-328. [CrossRef] [PubMed]

29. Pradhan, P.; Fischer, G.; van Velthuizen, H.; Reusser, D.E.; Kropp, J.P. Closing yield gaps: How sustainable can we be? PLoS ONE 2015, 10, e0129487. [CrossRef] [PubMed]

30. Alston, J.; Pardey, P. Agriculture in the global economy. J. Econ. Perspect. 2014, 28, 121-146. [CrossRef]

31. Coelli, T.; Rao, D.S.P. Total factor productivity growth in agriculture: A malmquist index analysis of 93 Countries, 1980-2000. Agric. Econ. 2005, 32, 115-134. [CrossRef]

32. Ananth, G.S. Returns to Investment on Agricultural Research in Karnataka-An Analysis of Major Field Crops. Ph.D. Thesis, University of Agricultural Sciences, Bangalore, India, 2004.

(C) 2018 by the authors. Licensee MDPI, Basel, Switzerland. This article is an open access article distributed under the terms and conditions of the Creative Commons Attribution (CC BY) license (http:/ / creativecommons.org/licenses/by/4.0/). 